\title{
Commitment and control
}

\author{
Teamwork as management tool in a welfare state \\ bureaucracy
}

\begin{abstract}
Teamwork is a well-known management technique for eliciting commitment and exerting control in private companies. However, less is known about how teamwork operates as a management tool in welfare state bureaucracies. Tying critical management and street-level bureaucracy studies, this article explores teamwork as a key component in the normative control of streetlevel bureaucrats within the Swedish Social Insurance Agency. Based on extensive ethnographic research, the analysis demonstrates how teamwork functions as a subtle steering device in public management. The analysis identifies teams as: a) performative tools; b) cushioning structures; and c) "moral corsets" on caseworkers. By the seamless linking of vertical and horizontal governance mechanisms, teamwork was instrumental in achieving organizational targets, thereby changing the nature of casework and reducing caseworkers' discretion. The findings call for more research on the normative shaping of caseworkers under new forms of public management.
\end{abstract}

Keywords: caseworker, institutional ethnography, normative control, street-level bureaucracy, teamwork

TEAMWORK IS A widely used management technique for eliciting commitment and exerting control in private companies. Teamwork is part of a corporate culture whereby employers seek to simultaneously achieve the twin objectives of employee commitment, pleasure in work and efficiency goals (e.g. Barker 1993). As such, teamwork is part of a wider management strategy to align subjects with organizational values; through management based on horizontal structures, team-building, releasing of co-worker potential, the "infusion" of shared values and the mobilization of positive feelings in order to achieve organizational goals. Hence, teamwork may operate as a subtle technique for the exercise of normative control (Kunda 2006[1992]).

Teamwork as technology of governing has travelled from the private sector to welfare state bureaucracies. Less is known about how teamwork operates as a management tool in the context of such formal, rule-governed and often hierarchical organizations. Of special interest, we suggest, is the role of teamwork as a management tool in street-level bureaucracies, where front-line staff traditionally have been viewed to have a certain 
discretion in applying general policy to individual cases (Lipsky 2010[1980]). As argued elsewhere (Jacobsson, Wallinder \& Seing 2020), the street-level bureaucracy literature (in the tradition stemming from Lipsky) has tended to conceive front-line staff as the outer edge of a hierarchical governance chain and focused primarily on street-level bureaucrats as individuals. It is relevant to ask how such a collective work process as teamwork affects street-level bureaucrats' work, including their discretion scope.

Moreover, street-level bureaucrats typically face contradictory demands, treating customers as unique persons which requires flexibility and discretion, and following the logic of bureaucracy which brings inflexibility, strictly treating clients on the basis of formal rules and routines (e.g. Lipsky 2010). While firms are targeted to profitmaking, public officials have to achieve multiple objectives at once, conforming to cost efficiency requirements, providing good service, assuring rule of law principles and meeting political targets, which renders their normative regimes more complex. This article explores how teamwork operates as management tool in a welfare state bureaucracy characterized by such a complex normative regime and the role teamwork plays in the management of discretion. The article shows how normative governance can operate socially to achieve management goals, shaping casework in more subtle ways than pointed out in the classical street-level bureaucracy literature.

This article focuses on governing through teamwork in the Swedish Social Insurance Agency (SIA, Försäkringskassan). Based on rich ethnographic research conducted in five local SIA offices, the article considers teamwork as a key component in the normative governance of the casework - and caseworkers - in this agency. The analysis addresses the following research questions: 1) Which role does teamwork play in the normative control of SIA caseworkers?; and 2) In what way does teamwork affect the nature of casework when used in a street-level bureaucracy?

The article contributes a rare ethnography of teamwork in a welfare state bureaucracy. The ethnographic data allow us to conclude that while management uses teamwork strategically to reach organizational objectives, it is the social mechanisms at work within the teams that give teamwork its normative power: the team-members developed their own self-regulatory systems of commitment and control. Secondly, by tying concepts from critical management studies to the study of street-level bureaucracies, the article enriches the latter literature by showing how normative governance can operate socially in ways that shape casework in more subtle ways than pointed out in the classical street-level bureaucracy literature. The analysis indicates that teamwork helped to create acceptance of the narrowing down of discretion. Thirdly, the article provides a conceptualization of the role that teamwork performed, of possible relevance beyond the studied agency, identifying teams as a) performative tools; b) cushioning structures and c) "moral corsets" on caseworkers. By the seamless linking of verti$\mathrm{cal}$ and horizontal governance mechanisms, teamwork facilitated the organizational performances in the SIA, while simultaneously transforming the way discretion traditionally seen as a defining characteristic of street-level bureaucrats (e.g. Lipsky 2010) - was practiced. 


\section{Previous research findings}

This article seeks to bridge two literatures that seldom speak to each other: the study of street-level bureaucracies (SLBs) and critical management studies. As new management models imported from the private sector constitute alternative ways of securing organizational loyalty and controlling caseworker action and discretion, much is gained from such cross-fertilization of research traditions, this article suggests.

That new forms of public management transform SLBs in various ways is evidenced in the many studies of how performance-based systems and standardization affect individual caseworkers as decision-makers and their discretion (e.g. Brodkin 2011). This article focuses on teamwork as a management tool and the role it plays in the organizational control of caseworkers.

This article argues that the collective processes of governing casework and controlling caseworker discretion deserve more research attention. The pooling of discretion to collective settings has only recently become the topic of street-level bureaucracy research (see Rutz \& de Bont 2020). Rutz and de Bont (2020:284) distinguished between collective discretion (referring to occasions when workers pragmatically involve others on their own initiatives) and discretionary room (when a degree of freedom is formally granted to teams). However, teamwork, as studied in this article, differs from both these ideal types, as teamwork is implemented on the initiative by management, not the workers; and secondly, the formal decision remains with the individual caseworkers. Instead, teamwork is essentially a strategic attempt by management to govern collective work processes, thus shaping in a more subtle way the front-line workers' beliefs about their mission as well as the way they use their discretion. To understand and conceptualize such processes, it is useful to draw on insights from governing by teamwork in private companies, stressing teamwork as a management technique for eliciting commitment as well as exerting organizational control.

On the commitment side, the shift away from hierarchical control towards autonomy and self-management has attempted to achieve job commitment and satisfaction through sociability and self-actualization at work, along with more the instrumental objectives of improved performance and organizational efficiency (e.g. Barker 1993; Procter \& Mueller 2000). Employee motivation is supposed to be enhanced through more "ownership" of the work and by producing positive group spirit (Benders \& van Hootegem 2000). Operating through such social and emotional mechanisms, teamwork group enhances feelings of community (Barker 1993:422).

On the control side teamwork has been seen as producing more subtle and indirect, normative forms of control, which are more difficult to resist because less apparent. Operating through collective responsibilization and peer control, teamwork is both disciplining and self-disciplining (e.g. Knights \& McCabe 2003; Saario, Räsänen \& Hall 2017). Barker (1993) even saw self-managed teams as a "tightening of the iron cage", achieving a concerted form of control "more powerful, less apparent, and more difficult to resist" (Barker 1993:408) than that of the former hierarchical governance. His ethnographic study of team interactions in a manufacturing company enabled him 
to see how members developed a system of value-based normative rules that controlled their actions more powerfully than the former system, and which became increasingly rationalized and naturalized over time (Barker 1993). Hence, teamwork can produce strong identification and loyalty with the organization, aligning individual motivation and organizational rationality (e.g. Knights \& McCabe 2003).

However, teamwork as management strategy may also evoke resistance. Knights and McCabe (2003) found that some employees displayed awareness of management's attempt to mold them and rejected the pressure to conform (Knights \& McCabe 2003). Ezzamel and Willmott (1998) found that teamwork produced unity against management. As teamwork is typically a management-driven initiative, any autonomy implemented tends to be autonomy on management's terms. Consequently, the employees may experience the contradiction that management expects independence while teamwork demands conformity to team discipline (Knights \& McCabe 2003:1615).

So far, there has been less research on teamwork in the public sector. Most research has been on teamwork in the health care sector, where the existence of strong professional norms may undermine the normative influence of teamwork (e.g. Finn, Learmonth \& Reedy 2010). Moreover, teamwork in the healthcare sector is based on a different rationale: to bring together different roles and competencies to achieve a holistic solution for the patient. As studied in this article (just as teamwork in companies), teamwork rests on the rationale of producing unity in thinking and acting, based on the logic of similarity rather than dissimilarity of competence. How does such teamwork blend with the logic of a state bureaucracy? And, for the purpose of this article, how are street-level bureaucrats affected by the governing through teamwork? Here research is scarce.

A few studies of teamwork in the UK tax agency exist, in the context of LEAN management. Procter and Currie's study (2004) of target-based teamwork found increased reciprocal interdependence among team members, both in regard to tasks and outcomes, but downplayed the normative elements of teamworking. Carter, Danford, Howcraft et al. (2011) found loss of employee control and discretion and the prioritization of target-driven work at the expense of non-target-driven work. Some employees found their public service ethos undermined. Procter and Radnor (2014) found some evidence of loss of employee discretion, but also that some employees felt empowered by greater predictability in the work and a greater identification with the organization. The teams performing better in terms of reaching the targets, felt more positive team spirit.

Only two previous studies of teamwork in the SIA exist. Holmgren Caicedo, Mårtensson Hansson and Tamm Hallström (2015) found that despite talk of autonomy, staff was designated from above, which led to conflicts in the teams. Nevertheless, teamwork increased caseworker autonomy in the sense of shared responsibility for cases. However, the highly formalized work of 'continuous improvement' that was in focus for the teamwork at the time left less time for substantive discussion of cases (Holmgren Caicedo, Mårtensson Hansson \& Tamm Hallström 2015). Similarly, Fransson and Quist (2018) found that teamwork was supported by caseworkers when 
the aim was to assist in casework and help achieving production targets, rather than to take part in quality work.

With the exception of Fransson and Quist's (2018) study of an organizational experiment in the SIA, none of the mentioned studies of teamwork in street-level bureaucracies were based on ethnographic research. To capture the normative influence of and through teamwork, ethnographic research is useful - if not even necessary - since it is the social mechanisms at play that gives teamwork much of its "bind". Studies of the collective processes of teamwork in street-level bureaucracies are extremely rare, however. One exception is a study of teams within the social services in Finland which found that team-meetings served as arena for collective responsibilization. These authors noted that informal decisions were carried out in team-meetings regarding the future of clients of which the clients may be unaware (Saario, Räsänen \& Hall 2017:190-192).

To conclude, in order to understand the role that teamwork play in the normative governance and control of staff, it is important to see what is accomplished in the social interaction; our ethnographic and essentially sociological approach allows us to do so. Solely interview data might underplay the peer pressure involved in teamwork, as well as the negotiations taking place around the cases discussed.

\section{Theoretical framework: Normative control}

We follow Adair's definition of a team as a distinctive class of group, which is more task-oriented than other groups, and which has a set of obvious rules and rewards for its members (Adair 1986). In the analysis we pay particular attention to the social rules - norms - as well as the social and emotional rewards entailed in teamwork within the SIA, in order to investigate the normative control exerted and unfolding in team interactions in this agency.

Etzioni (1961) noted that bureaucratic work organizations traditionally have been governed based on instrumental rationality, through either rules or rewards (or both). In addition, he wished to point to the use of normative control. Kunda (2006) then used this notion in a study of normative control in a high-tech company. He defined normative control as the attempt to elicit and direct the required efforts of members by controlling underlying experiences, thoughts, and feelings that guide their actions (Kunda 2006:11). Normative control offers increased freedom rather than tyranny, operating as "an appeal to the potential existing in people" (Kunda 2006:14). To the extent staff are shaped, that shaping is framed as a process of education, personal development or growth (Kunda 2006:6), which resonates with the typical discourse on teamwork on increasing autonomy and enabling workplace learning.

Moreover, Kunda (2006) was interested in the ways in which a strong organizational culture could work as normative control by providing norms for staff; in our case, norms for the appropriate caseworker. Organizational rituals served as mechanisms by which the organizational culture got internalized, infusing participants with "the right mindset and the appropriate gut reactions" (Kunda 2006:93), thus influencing what they ought to think and feel and what they should regard as proper and possible. 
McKinlay and Starkey (1998:10) argued that normative control gets effective to the extent that it is sustained by practices and discourses of daily organizational life. An ethnographic approach is hence useful to assess the extent as well as the way control is reproduced by organization members in the daily work.

Teamwork is essentially a social process, even though, as an organized form of social interaction, it is targeted at achieving clearly defined objectives. We argue that it is those social forces at play that gives teamwork its normative power. In our understanding, teamwork is performative - it accomplishes things; for instance, producing social relationships and a normativity that mobilizes actors in a particular way. Thus, the focus of analysis is on the mobilization of commitment and exertion of control at play in teamwork, as well as on what is accomplished by the team interactions in terms of shared understandings, common feelings, organizational loyalty and identification. We look at both the normative control carried out by management and the normative control (re)produced in the collegial interaction in the local offices. As Barker (1993) noted, value-based interactions among the team-members could become a social force that controlled their actions even more effectively than the organizational rules from above prescribed.

\section{Data and method}

The SIA is one of the largest state bureaucracies in Sweden, employing over 14,000 staff. The SIA caseworkers lack a common educational background. Even so, they qualify as street-level bureaucrats in having to apply general policy to individual cases. In formal terms, they have a certain discretion (within the SIA the term scope for assessment [bedömningsutrymme] is used). Coordination of caseworker action in such an agency is key and teamwork is a management-strategy aimed to achieve more uniform assessments, among other things. All SIA offices throughout the country have implemented teamwork as a working method, for caseworkers, managers and specialists alike. This article focuses solely on caseworkers administrating the sickness insurance.

This article draws inspiration from institutional ethnography (Smith 2005), for which the social is the focus of study, as located in people's activities as they are coordinated with those of others (Smith 2005:59, 70). Hence the social organization of action is in focus. Herein, we investigate what is achieved by teamwork in terms of coordination of action and how norms are conveyed and enforced in the social processes. This allows us to see how normative governance operates through teamwork in the SIA.

The analysis is based on ethnographic observations of the daily work in five local SIA offices located in two Swedish regions, during 2016-2017. Apart from proper team-meetings, staff-trainings, leadership-trainings, co-worker meetings, quality controls, interaction in lunch rooms and corridors were observed. The reason for this wider focus of attention was firstly to capture the organizational context in which teamwork as institutionalized working method was embedded, and secondly, to see the role teams played in the everyday work in the offices in order to assess the fuller extent of the 
normative power of teamwork. The observations were recorded in extensive field notes. About one intense month of fieldwork was conducted at each local office.

Moreover, the analysis draws on 38 qualitative, semi-structured (recorded and transcribed) interviews with staff in those local offices: caseworkers administering the sickness insurance, their local managers as well as local specialists on the sickness insurance and "insurance medicine advisors" (medical doctors). In addition, for the background information on organizational governance in the SIA, 16 qualitative, semi-structured (recorded and transcribed) interviews were conducted at the head office in Stockholm during 2015-2016.

The SIA is a highly centralized agency and for such an extensive ethnographic multi-site study as ours, consent had to go through the head office. Consequently, the head office's selection was made in negotiation with the local office management. Once consent was given, we were granted full access to all activities we wished to attend in the selected offices. It should be noted that the offices studied were placed in two regions with a lower average of sickness benefit days than the national average, and four out of the five offices studied performed better in the sense of exceeding the organizational goals in relation to granted sickness benefits. Such offices have more time to take part in time-consuming research, but it could not be ruled out that the head office wished to make a "good impression" on researchers. We are aware of this risk in the analysis and note (later on) that the few signs of resistance that appeared in the ethnographic study were displayed in the "less-performing" office.

We used an abductive process of analysis. The focus on the conveyance and reinforcement of norms was guided by the theoretical framework on normative control. The conceptualization of three roles that teamwork played in the normative governance of casework stems from an inductive process of analysis of the ethnographic and interview data.

\section{Teamwork in the normative governance in the SIA: The context}

To understand teamwork in the SIA, it is important to know the tasks and missions formally assigned to caseworkers in this agency, as well as the organizational objectives and management priorities at the time of the study. These form the normative regime under which caseworkers worked in their every day. The formal task of SIA caseworkers is firstly to administer the sickness insurance and assess and control the clients' eligibility to benefits, and secondly, to coordinate rehabilitation for clients in need of support. Since 2008, caseworkers are also required to follow a fixed time schedule for assessments of individuals' work ability and right to sickness benefits at specific intervals (called the "rehabilitation chain"). Despite the continuity of the formal tasks, management priorities have shifted considerably (e.g. ISF 2018).

When teamwork was first introduced in 2012, it was as part of implementing LEAN and a management ideology based on "value-based governance" (away from "command- and control" models of steering as well as strict management by objectives and results), with strong customer focus and notions of "coaching leadership" and 
"continuous improvement" (Holmgren Caicedo, Mårtensson Hansson \& Tamm Hallström 2015). The political instruction to the SIA at the time was to increase the public's confidence in the agency and in the sickness insurance, which for a long time had been low, as well as making the agency more attractive as a workplace. Teamwork was introduced as a guiding principle in the entire organization. In relation to caseworkers, teamwork was intended to achieve several objectives at once; collective learning among caseworkers, increased job satisfaction and the achievement of efficiency goals. During this period, teamwork was oriented toward increased autonomy in casework as well as caseworkers' contribution to quality work (as part of "continuous improvement").

In 2015, a new Director-General was appointed and a shift in management ideology took place, emphasizing correct application of the law and uniform case assessment as well as a return to stricter management by objectives. Importantly, in 2016, the center-left government introduced a numerical target for the sickness absence rate in Sweden: that the sickness benefit rate should not exceed 9.0 days per individual and per year in 2020, as national average. The SIA was commissioned to contribute to reducing the Swedish sickness absence rate by making sick leave periods fewer and shorter. The Director-General emphasized that caseworkers were prompted to "make things right from the start" in case-management and "increase the quality of the investigations", ensuring that "the right person receives the right compensation" (Försäkringskassan 2016:2). Teamwork was maintained as management tool but was reoriented toward achieving these goals: stricter eligibility control, timely assessments and, as a consequence, lower sick absence rate. Interviewed managers were very clear that the number of rejections and withdrawal of benefits had to increase, and the "development curve" was displayed at office meetings monthly.

Thus, at the time of this study, the 9.0-vision was a key component in the normative regime of the agency, around which a collective mobilization of commitment took place. The managers placed "9.0" at the center of attention in the (observed) local office meetings. A local manager could begin a speech at a workplace meeting by saying: "Everything we do must affect the target 9.0". The mobilization of commitment around the current goals was achieved by the distancing in relation to the "bad past" when the application of the insurance had been too generous. Interviewed managers argued that the customer-orientation of the former period had meant a too generous approach, and many caseworkers - but not all - welcomed the signal to be more restrictive in granting benefits. The stricter criteria for benefit eligibility were framed as a way to "protect the sickness insurance"; this was spelled out as the core task by the top management but was also adapted in the local lingua of caseworkers, as here:

We have the world's best sickness insurance. But unfortunately we don't protect the insurance [...] far too many receive sickness benefits. And that is my greatest fear (caseworker)

The 9.0 vision came to symbolize the heroic role of SIA staff in protecting the sickness insurance against "excessive usage" (see also Altermark 2020). The common 
identification as gatekeeper to, and guardian of, the sickness insurance rendered meaning to the work and gave a shared sense of the purpose, evoking a sense of pride among SIA staff. It was this normative order that the SIA teams were to serve. The self-understanding of employees as parts of an obedient and high-achieving administration - delivering what was currently expected - was salient. This strong organizational culture, which was largely shared by managers and front-line staff alike, served as a basis for normative control, and one in which teams were instrumental. We now turn to the analysis of the normative governance and control exerted in and through teamwork.

\section{Normative control through teamwork: Empirical analysis}

The first empirical section focuses on teamwork as a management tool for normative control in the SIA, aiming to achieve goal consensus as well as reducing the scope for deviations in casework. The second section focuses on teams as normative enforcers, key for the reproduction and naturalization of norms in the local offices.

\section{Teamwork as management tool in the SIA}

Teamwork was a cornerstone in the normative governance of casework. During the period of study, all SIA employees were divided into teams: managers, specialists and caseworkers alike. Caseworkers were sorted into teams with approximately $8-10$ members and organized according to the geographical area covered. All teams had a team-coordinator assigned to them, a caseworker selected by the manager to be a link between management level and team-members. The ideal was that the team should be self-governing; thus, caseworkers were first to ask their colleagues for advice in casework, while managers and specialists should be consulted only as a last resort. Even if formally each client had one specific caseworker assigned to him/her, each team shared a collective responsibility for the cases within the team. Consequently, in formal terms, the introduction of teamwork in the SIA meant some changes in the work organization as compared to before. The caseworker teams shared joint responsibility of cases within the team, and team-members were to back-up each other in times of high work load or sick absence. Before teamwork was introduced, caseworkers had responsibility only for the cases assigned to the specific caseworker. In the local offices studied, team performance and productivity were in focus rather than individual performance, reinforcing the notion of teams as the main performing unit. At team level, timely assessment in relation to the rehabilitation chain was the main focus of follow-up while at the office level, performance in relation to 9.0 and the numbers of rejections and withdrawals of benefit were measured and communicated.

Formal team-meetings took place on a weekly basis, in which difficult cases were discussed. However, informal team interactions were considerably more extensive and frequent. Daily meetings around team-boards, where team-members gathered and discussed case-load and team productivity took place in the offices studied. This was 
encouraged by management, with the intention that teams were supposed to give "impulses" up in the organization when encountering problems that could not be solved within the team. As the team shared the responsibility for the cases, team-members helped each other with case-management when needed. On a more informal basis, team-members were resources for each other when problems arose in the casework. Thus, the teamwork was both organized in a formal setting through regular teammeetings, and in an informal way where caseworkers turned to each other "ad hoc". Both aspects of teamwork are important in order to understand the extent of the normative control exerted in and through teamwork.

\section{a. Team creation as normative control of caseworkers}

The sorting of caseworkers into teams was made by the local management, thus from above. SIA staff had to accept teamwork as the model for the work. A controller described:

When you take on this role [as a caseworker], you are to work in a team. Full stop. That's the way we work. And we have had the discussion with some caseworkers, that have said "I do a great job, and I do not want to work in a team". Then we have to say, "well, making exceptions for you does not work. You have to [be in a team], and to develop in your work you have to take on this way of working. This is how we do it here, we understand that you might need time, and you can take it in your pace. But this is where you are going", and it has turned out really well. It is a question of maturing - a lot of issues related to how much can one show of oneself and how can one cooperate with others.

The caseworkers' ability to work in teams thus was conceived be a question of maturity and a way to develop professionally. Maturity was used also to describe team-processes. Some teams were considered more mature than others. The controller described:

Well, there is great variation between the teams. Of all the teams that I meet, there are some that are mature and well-functioning. But I also meet teams that are not in the game. It is more like a group of people who are angry most of the time. [...] or a group of people that think lots of different things.

Teams were units expected to develop a common group thinking. As a way to improve and facilitate the group processes within teams, management in some local offices arranged teamwork trainings for the caseworkers. Specific sessions in team development with process-leaders from the SIA centrally were organized, in which challenges and advantages of teamworking were discussed. The teamwork training was performed with the regular teams, using them as examples and basis for discussion. The teams were to highlight their expectations on each other, and to articulate "team-agreements" that should guide their future teamwork: 
Well, we do our team-agreement for this year. What are the rules? And this includes everything from rules of the game, how we relate to each other in the team, it is about keeping time, the meetings, turning off your phones in teammeetings, prioritizing team-meetings, to talk respectfully with each other and so on. (caseworker)

Team-agreements were thus components of the normative governance of each team. Moreover, creating a feedback culture and "team promises" were reoccurring themes during the training. Team-members were encouraged to dare to give and receive feedback, conceiving of feedback as gifts to one another. This gift-giving can be seen as a way to reproduce the normative order and keep caseworker in compliance, as developed further later on.

Accordingly, giving and receiving feedback was considered as an important competence in teamwork, and something that had to be trained. When it comes to changing the behavior of team-members, the feedback was considered most efficient if it related to the emotions that a certain behavior evokes. The facilitator in charge of the teamdevelopment explained:

What a person has produced or done has an impact on all of us, on our team. For instance, when you made this, it made me happy. Or, when you are late, I become sad, irritated and impatient. Because it makes me think that you do not care about me or what we have agreed on. I feel as if I am not important to you. But we need to talk about emotions. And this can be difficult, if we are not used to doing so. But emotions can be happy, sad, angry, curious [...] if we express our own needs when giving feedback to others, it has a better turnout, if cooperation is our goal.

Team-training was thus one way of reaching mature, self-governing teams. However, there was a clear tension between on the one hand reaching mature, autonomous teams that were capable of controlling their own work, and on the other hand, the hierarchical governing structures. The top-down introduction to teamwork was noticeable. A caseworker described:

Well, we are supposed to be self-governing units. But it feels somewhat like a paradox. I perceive that we are an extremely hierarchical organization. I have asked about the degree of autonomy, or freedom, we have as a team. In how we organize. And as I understand, we do not have that much freedom actually. What every individual does in the team, and how the team selects its members, is nothing that we can have an influence on. It all comes from above.

While the teams were embedded in a discourse of autonomous units capable of making their own decisions, what was perceived as the right way to do casework was not developed by the teams, but prescribed by management and the specialists in a hierarchical structure. 


\section{b. Coaching as normative control}

Nevertheless, teams as self-governing units in charge of their work, was considered by local management as the key to success in relation to improved results. The expectation was that problems should in the first place be treated in the team. Specialists on the insurance and medical advisors were available as resources for the team for consultation and guidance, but only when the resources within the team were exhausted. The introduction of teamwork in the SIA was connected to a transition in leadership style "from cop to coach" (Procter \& Mueller 2000:13) and was presented as an important aspect of organizational learning.

In the offices studied, teamwork was clearly used strategically for managing caseworker discretion in order to meet the target of 9.0, and it was stated out that it was by stricter eligibility control that this target could be met. This type of governance was welcomed by many caseworkers who were looking for support and confirmation that they assessed cases as intended by the organization, thus in the "right" way. Difficult cases were discussed in the team, with the supportive coaching by specialists with medical training. One caseworker described the benefits:

You get in like in black and white, "am I thinking the right way? Is it reasonable to have these problems as a consequence of a certain diagnosis?" Because we are not trained in medicine, not at all. We only interpret the medical documentation we receive.

Teamwork concerns the horizontal interaction between co-workers and "coaches". The notion of coaching leadership and the stress on continuous learning played down the hierarchical relation, building on governance by encouragement and collegial support rather than order-giving. The low-profile participation of specialists in the teamwork, as support function to a self-reflecting team, allowed team-members to feel that they were the ones doing the thinking, after which they got the approval of the specialist. This normative control became effective in creating conformity in assessment and action while evoking less resistance than "command"-style leadership.

With the introduction of teamwork, team performance rather than individual performance was in focus. From management's side, the teams were considered one of the success-factors in achieving the good numbers in relation to the set goals. In an observation of a managers' meeting, one manager told that her office had started a couple of years ago to extract indicators on length of sickness periods, and how the cases were assessed. Fairly soon, the teams started to ask for these indicators themselves. The managers noted that teams asked for statistics on a more frequent basis than managers could even deliver. For the managers, delivering statistics more often than once a month did not make much sense. However, the teams kept asking for more frequent feedback, illustrating the caseworker commitment to organizational goals.

Moreover, the comparison between team-members could be used to govern caseworker behavior. One manager described how she worked with caseworkers who deviated in relation to assessments done by either granting or declining more applications than 
other team-members. This matter was processed in dialogues with the staff, by asking direct questions. "Can it really be reasonable that [name] has done seven rejections, while you haven't done any?". This soft coaching of team-members was used strategically by management to reach set goals and keep caseworker performance in line.

To conclude, even if the teams were posited as self-governing and the goal was to have them "take ownership", the autonomy was clearly circumscribed and the organization decided what was the "right" way to use the discretion. Previous ways of working were disqualified, with the motivation that the application of the law had been far too generous (ISF 2018; Altermark 2020). Moreover, referring problem-solving to the teams was also a way to encourage peer control to be exerted by team-members in relation to each other.

\section{Normative reproduction through teams}

We will now look at how the normative control entailed in teamwork was taken on board and enforced by the caseworkers, identifying three roles that teams played in reproducing the normative order.

\section{a. Teams as performative tools}

The first role was that of teams as constituting performative tools, in support of the (current) normative order. We understand teamwork as performative in that it accomplishes things, (re)producing a normativity that mobilizes actors in a particular way, in this case in accordance with current management priorities and organizational ideals. In our analysis, teams were key instruments for performing performance (cf. Clarke 2005:218), with team-members striving to collectively excel in organizational goal attainment. To be perceived as high achiever was important. In several of the offices, the focus on goals and targets was visualized on team-boards openly displaced in the office. Both statistics related to work loads of team-members and goal achievement of the team was presented. The visualization of team performance displays how teams can be used as performative platforms in mobilizing commitment to organizational goals as well as in mainstreaming casework. A caseworker - or a team - stood out, if performance was not "in line". In the teams, deviations became the center of attention, and the target for correction when fellow caseworkers suggested possible ways of improving the work. Thus, the visualizing of casework became self-regulating; the manager did not need to interfere - the team did the work on its own. Reaching good numbers - and achieving organizational goals - boiled down to the work performed in the teams, by the caseworkers. The teams took collective "ownership" in relation to the results, along with - and even beyond - what managers expected from them.

In the daily work, the teams were important in relation to how caseworkers understood their work. One example of the performative role of teamwork was when teams invented reward systems when reaching organizationally set goals. Each team had their own whiteboard, and in some teams, stars as symbols were applied on the board to indicate when goals had been met, both goals in relation to production and work environment. When a certain number of stars were achieved, the team rewarded 
itself, for instance by going for after-work together. The rewards were initiated by the team, paid for by the team-members and performed outside of working hours. These self-initiated rewards illustrate the degree to which team-members had internalized the organization's goals and ideals, and shows how organizational goals were transformed into personal goals (McKinlay \& Starkey 1998:9) through the social processes in and around teamwork. The reward system developed by this team was not enforced by managers. Instead, the team itself had invented incentives to achieve organizational targets, thus reproducing the organizational norms. Such "pleasurable practices" (Eriksson 2015:125) was a way to develop the ties among team-members as well as the affiliation to the organization, strengthening the sense of community on joint mission. The subtle way of governing through teams thus meant that self-regulating systems to enhance goal achievement were developed.

The competitive spirit - and the satisfaction of achieving - can be seen in relation to how caseworkers and teams reacted to measurement and the use of indicators in the team. As discussed above, some teams asked for more frequent feedback on their joint performance, than their managers found meaningful to provide. Just as in Knights and McCabe's study of a call centre, performance targets signaled that the staff had met management's expectations (2003:1608), and was thus loaded with positive feelings and a sense of security; with clear objectives and indicators the caseworkers knew when they had done a good job. It became unproblematic for the caseworkers to relate to these targets and indicators. In one of the offices studied the team boards were used differently. The tables did not display any information on team performance; instead, announcements about the upcoming office Christmas party or general news from the head office was displayed. The office in question was considered to be in the less performing group. We interpret this board usage as a sign of low-profile resistance to current top-management ideology.

Moreover, team-meetings were occasions for caseworkers to prove that they possessed the right qualities, being able to make the right - including tough - decisions. By enacting performance, collective identities as high achievers and loyal organization members were (re)produced. To be happy about good numbers - even if these signaled that more clients were declined benefits - was something expected and natural, and the failure to feel that way signaled that one might not belong there. At office meetings, the collective achievement in relation to the official goal of 9.0 was regularly reported, and increases in the numbers of rejections or withdrawals of benefit could evoke feelings of pride and even joy, among managers and caseworkers alike.

\section{b. Teams as cushioning structures}

The second role played by teams was that of "cushioning structures", reducing normative frictions entailed in the casework. The teams had an important role to play for caseworkers both as an arena for support in the technical aspects of casework and for giving and receiving social support. This support function is important for understanding the role teams played in goal achievement; team-members took joint responsibility for the assessment of cases being in line with organizational goals and for the need 
of support team-members may have. Teams thus served as "cushioning" structures, supporting individual caseworkers in difficult case-assessments but also serving as a collective "cushion" in relation to a "hostile" surrounding and the negative media publicity that the SIA often face. This allowed them to fully embrace their role as caseworkers and protected against outside criticism as well as their own inner dissonance.

In the team-meetings, the work load and the work situation of each caseworker was visualized and discussed. Caseworkers expressed that this visualization and the continuous discussion with the team-members had given them a stronger feeling of security and peer support in their daily work. The heavy work load and complicated regulations, how to prioritize among the cases, and how medical documentation was to be interpreted, were matters discussed in the teams. The notion of "our cases" - as opposed to "my cases" - was an important aspect of teamwork. The caseworkers stressed the importance of having team-members to consult in cases that required complicated processing. The team became a platform for sharing experiences and knowledge. This was perceived as a great support by caseworkers who were more inexperienced in their work, and was also rewarding for the more experienced ones who could share their knowledge and expertise with more novel caseworkers.

The social support to team-members was equally important as the technical help. The shared responsibility for cases, the ongoing discussions on how to prioritize and how to decide in complicated cases created a protecting support system around the caseworker. Making a difficult decision became less emotionally constraining when the decision had been discussed, supported and legitimized by fellow team-members:

Like "what do you think, and how do you view this case? And this medical document?" And we think, all of us think [together]. And it feels good to know. If I am insecure, I feel like, if I have discussed with my colleagues, then I can go back and contact the client. It is not just me [behind the decision]. (caseworker)

Teamwork helped reduce insecurity among caseworkers. Also, the sometimes very hard personal circumstances around the clients affected the caseworkers, and support was sought and provided by the team. In the most complicated cases when decisions were questioned by the clients, the case could be handed over to a team-colleague. One manager here confirms the role teams played to support caseworkers when making difficult decisions:

When it is hard, and when clients are upset, the caseworkers now have the team behind them - and the specialists, and the managers. That gives support in the back, a feeling of "I am making the right decision". Otherwise, when you are on your own, you start to discuss with yourself - did I really make the right decision? Or am I too tough? When you have taken the case to the team, you feel more safe and secure, as a caseworker. You get more arguments. Even those caseworkers with great difficulties in making rejections and withdrawals, they also feel more comfortable. (local manager) 
The role the team plays can thus be understood as a cushioning structure for the caseworker - protecting the team-members from having to tackle the challenges in the work on their own. Teamwork thus facilitated the tough decisions, such the rejections or withdrawal of benefits. From management's perspective, it made goal achievement smoother.

\section{c. Teams as "moral corset"}

The third role identified was the team as a "moral corset" on the team-members, which is related to the notion of teams as platforms for organizational learning. The shared team discussions, as opposed to individual consultations with managers and specialists, was seen by management as a way to make the work more efficient and secure more uniform assessment of cases. In the teamwork, caseworkers learned together and from each other, but teamwork also created a moral pressure to comply to the common norms within the team. Uniformity and the feeling of "we all work in the same way" were reinforced. The teamwork prevented the caseworkers from too sharp deviations in their casework - too many rejections or too many approvals. In the offices studied, the management expressed the allowance for deviance to be fairly narrow; they did not want any caseworker - or team - to stand out.

The team can thus be said to have the role of a "moral corset" for the caseworker - keeping the right shape and keeping the caseworker in line with what was perceived as appropriate behavior in casework, but also preventing the caseworkers from becoming too independent in their work, creating a pressure on the individual caseworker to comply. The following caseworker described her perception of the team as both supporting and controlling:

There is an enormous group pressure, of course ... Above all, the team is there for us to support each other. But I don't see it only like that. It increases the group pressure enormously. Like, I don't want to be a burden for the team. You don't want to have bad numbers for the team. I am new here, and, well, it is not really healthy.

Activities around the teams, such as the team-training, supported the normative impact the team had on its members. As we saw, focus in the capacity-building was placed on creating a feedback culture and the creation of team-rules. Team-rules developed by the team was a way to create a unified team with shared understanding of what was perceived as appropriate within the team, increasing the level of consensus. The team-rules can be seen as a method that enforces the moral corset on the caseworker - negotiated rules are not to be questioned. As we saw, the team-training focused on the expectations team-members had on each other and as the rules were not placed on the team by management but developed by the teams, they also become more enforcing - and more difficult to oppose for caseworkers.

The emphasis on a feedback culture within the team supports the notion of a moral corset on team-members and helped creating conformity among team-members. There 
was a strong notion of creating team-members that comply with the norms of the team. To challenge the norms and rules articulated in the team became challenging. Not only the actual casework was at stake here, but also the emotions and the wellbeing of the fellow team-members. This understanding of a feedback culture in the teamwork became a subtle way of governing caseworkers to perform in line with organizational goals and norms. The transparency around performances also created incentives to comply with norms and expectations. The comparisons between offices, teams and even individual caseworkers, can be seen as one way to create consensus and avoid too great discrepancies in the casework. To avoid shame and not to put co-workers in a bad situation, team-members were inclined to perform in line with the expectations. Compliance was important - to do things in the right way - and much like rituals, it had to be performed. This also meant that management control was in many cases replaced by peer- and self-control.

But the function of a corset is also to help keeping up a straight posture. Acting according to the norms and performing along expectations evoked pride among the caseworkers studied, and allowed team-members to feel they were on a joint mission protecting the insurance for the future - regardless of the views of the world around.

\section{Discussion}

Drawing on Kunda's notion of normative control as the attempt to elicit and direct the efforts of organization members by guiding in their thoughts and feelings guiding their action (2006:11), this article investigates the role of teamwork in the normative control of SIA caseworkers. This seamless form of governing, integrating hierarchical and horizontal governance mechanisms, seems a highly effective way of governing the SIA caseworkers in the sense of mobilizing commitment a specific goal (as for instance, the 9.0 vision) as well as mainstreaming the casework. Importantly, through the teamwork, normative control was spread in the organization. We saw that the normative order was maintained and reinforced by team-members through peer norms and peer pressure, also in the absence of specialists and managers.

The teams united around the self-understanding of caseworkers as guards protecting the sickness insurance and the welfare state, of which the 9.0 was a key symbol. The collective pride in performing in the direction of 9.0 was manifested by the teammembers and their local managers alike. The normative governance thus aimed at not only controlling caseworkers' way of acting but also affecting their emotional world. The strong identity of being obedient and high achieving was displayed, and performed, in and through the teamwork.

In the individual interviews, some caseworkers expressed concerns about policies they perceived as too strict, leaving them with little room for external contact with the healthcare providers and the employers of the sick-listed. Our point is that no criticism was expressed in the collective work processes. We interpret this absence as an effect of the strong normative control that - not only management but also other team-members - exerted on the individual caseworkers. The lack of opportunities for 
caseworkers to raise their voices has serious consequences for the organization, for instance in relation to staff turnover. Exit (leaving the job) became the main option available for caseworkers who were uncomfortable with the stricter policies. According to staff turnover data obtained from the SIA, the number of caseworkers within the sickness insurance that resigned from their work increased dramatically during this period. The data shows an increase from $7 \%$ in 2014 to $19 \%$ in 2019.

It was clear that not complying with the norms, and the current management goals were perceived as problematic. The managers' explicit position was: comply, or consider if SIA is the right work place for you. And if you are not a team-player - then working at SIA is maybe not the optimal place for you. This rhetoric of consensus was reproduced by the team: teams were to be characterized by good spirit and agreement, which readily suppressed more critical voices (sometimes expressed in the individual interviews). While teams could, in principle, develop group-norms and use the team support to mobilize against management (Ezzamel \& Willmott 1998), we saw few such examples in the teams studied. Only in the office performing below the national average (regarding sickness benefit rates) we saw small expressions of resistance. In line with Procter and Radnor (2014), we found that better performing teams in terms of reaching the targets felt more positive team-spirit. However, in our analysis the norm of maintaining a good team-spirit was in itself disciplinary and a way of upholding the normative order. The teams became self-disciplinary units in the service of current management priorities.

We can conclude that teamwork was instrumental in establishing and reproducing a culture of consensus in the SIA, whereby the scope for deviation or questioning was reduced while commitment to management goals was created also from below. This study confirms the previous finding that teamwork may achieve a naturalization of the normative order (Barker 1993), which becomes self-evident. That current management priorities got internalized by staff was illustrated in the reward system as well as the peer pressure exerted by team-members on each other to conform with team-rules and aspirations. Just as Barker, we found that the caseworkers achieved concerted control by reaching a negotiated consensus, based on which they could infer "proper" premises on how to think and act (Barker 1993:411f.). Teamwork aligned in a rather seamless way individual motivation and organizational rationality (e.g. Procter \& Mueller 2000:17; Knights \& McCabe 2003).

Finally, the question has to be raised about what teamwork does to the role of the street-level bureaucrat when implemented in a welfare state bureaucracy. Teamwork, through its collective responsibility for casework, challenges traditional understandings of caseworkers' discretion and rather independent role in policy implementation (e.g. Lipsky 2010). In our study, discretionary power was de facto transferred from the individual caseworker to the team and the assessment of cases perceived as difficult or complicated was processed and agreed on by the team - as a caseworker assembly. As official decisions are signed by the individual caseworker only, the client was completely unaware of this negotiation process (cf. Saario, Räsänen \& Hall 2017). Thus, even if the formal decision remained with the individual worker, the decision-making de facto 
involved the team-members providing advice as well as exerting peer pressure. We see teamworking in the SIA primarily as a management strategy for managing and controlling caseworker discretion - by invoking collective forces and social mechanisms.

Our study supports the de facto loss of individual caseworker discretion (Carter, Danford, Howcraft et al. 2011). However, this loss was by and large welcomed by the caseworkers, who appreciated the guidance and support from specialists as well as peers in the teamwork. Since the teams met caseworkers' need for support in case-processing, teamwork was fully endorsed by most of the caseworkers as long as the focus was on production targets and assistance in case assessment. We suggest that the acceptance of - and support for - the narrowing down of caseworker discretion must be seen in the light of the normative control exerted through teamwork and other forms of workplace meetings by which a normative infusion of the staff was achieved. Teamwork protected caseworkers from emotional dissonance as well as outside criticism, legitimizing the current way of working.

Thus, teamwork was efficient in achieving production results in the SIA similarly to a private company. However, in the public sector, normative regimes typically involve multiple, and sometimes contradictory, objectives (e.g. production, rule of law, service-orientation), making "performing for the public" (Clarke 2005) a complex and delicate matter. Moreover, in politically governed organizations, goals are often changing. The main objective of the sickness insurance is to guarantee an income during periods where the work capacity is reduced due to ill-health as well as facilitating a return to the labor market by coordination of rehabilitation measures. Yet, in the daily work, cases are assessed in relation to the shifting organizational goals. In the SIA, focus shifted from customer satisfaction and coordination of rehabilitation processes (2011-2014) to a stricter application of the insurance with focus on reduced number of sickness days and equal and timely assessments (2015-2018) - even though the legal regulation and formal mission had not been changed. The shifting operational goals place high demands on caseworkers and managers alike to be able to shift focus and redefine their understanding of a well-performed job. We argue that teamwork facilitated the reduction of goal complexity, affecting caseworkers' beliefs about their mission, and enabled organizational goal displacement by allowing to overall objective (income protection and the coordination of rehabilitation) to be overrun by another goal; in this case reduced sickness benefit rate. Teamwork made the transition from one goal paradigm to another smooth and even attractive for caseworkers. The task of coordination of rehabilitation (prescribed by law) as well as client contact was explicitly down-prioritized by management and caseworkers alike in favor of the vision of 9.0 (see also Fransson \& Qvist 2018; ISF 2018; Altermark 2020). Thus, loyalty, as (re)produced in teamwork, was placed with the current management goals and norms - rather than with bureaucratic administration of the law. The cushioning role of teams and their coaches meant that any external questioning of the agency's practice could be kept at a convenient distance.

We can conclude that teamwork facilitated the organizational performances and, by implication, the smooth implementation of welfare-to-work policies in the sickness 
insurance. After all, the vision of 9.0, as a mobilizing and positively charged target in constant focus of attention as well as a source of pride among SIA caseworkers, was first and foremost attained by increasing the rate of benefit rejections to an extent that exceeded the organization's own forecast (ISF 2018:16). In fact, the number of rejections of benefits after 180 days of sick-leave increased five times during the period 2015-2020, despite the fact that the Swedish government withdrew the goal of 9.0 in 2018 (Altermark 2020). In 2021, the government made a new instruction to the SIA explicitly stating that the agency should reach the goal of lower sickness benefit rate by preventive measures, rehabilitation and stakeholder coordination, rather than focusing on increasing the rejection rate (Regeringen 2021). This article suggests that to understand how such goal displacement could take place, we need to grasp the collective processes governing casework and the normative control entailed herein.

\section{Conclusion}

By investigating the role that teamwork played in the normative control of SIA caseworkers, this article has contributed an analysis of how teamwork may affect the nature of casework when used as a management tool in a street-level bureaucracy. We saw how the normative control operated through teamwork, and what team interactions could accomplish in terms of shared understandings, feelings, and organizational loyalty and identification. Teams as units for organizational control served as: a) performative tools; b) cushioning structures, and c) "moral corsets" on caseworkers. Teamwork contributed to establish and reproduce a culture of consensus on the one right way of thinking in assessment of benefit eligibility. It should be noted, however, that the SIA remains a very hierarchical organization; indeed, this study suggests that it is precisely the combination of hierarchical and horizontal governance processes that led to the narrowing down of discretion in the SIA - not necessarily horizontal forms of governance per se (which could in principle play out as increasing collegiality and caseworker autonomy (cf. Fransson \& Qvist 2018).

The teams studied reproduced the organizational norms from above, enforced them through group dynamics and pressure, thus naturalizing the normative order, including the vision of 9.0 as a "reasonable" level of sick days in Sweden. The team negotiations, by which team-members developed their own self-regulatory system of control, contributed to mainstreaming casework and was instrumental in creating acceptance for the narrowing down of discretion and in the shaping of casework - and the appropriate caseworker - beyond formal policy.

It should be noted that the selection of offices for this study may have contributed to the productivity orientation as well as the organizational pride and loyalty displayed (four of the five offices were high-achievers in terms of 9.0). Only in the office performing below the average we saw signs of collegial resistance to management discourse and norms from above. The finding suggests that identity as a high-achiever is self-increasing, thus performative, when reinforced in the collective work processes.

Finally, this study suggests that uncritically importing management techniques 
from the private sector may transform the nature of public sector operations, in this case the case-management. Especially, future research should focus more attention on the group mechanisms at work in governing street-level bureaucracies under new forms of public management. Cross-fertilizing critical management and street-level bureaucracy studies opens new venues in such endeavors.

\section{Acknowledgement}

This research was funded by Riksbankens Jubileumsfond (grant SGO14-1192). We gratefully acknowledge the generous participation by the SIA staff, and Ida Seing's contribution to data collection.

\section{References}

Adair, J. (1986) Effective teambuilding. London: Pan.

Altermark, N. (2020) Avslagsmaskinen. Stockholm: Verbal.

Barker, J.R. (1993) "Tightening the iron cage: Concertive control in self-managing teams”, Administrative Science Quarterly 38 (3):408-437. https://doi. org/10.2307/2393374

Benders, J. \& G. van Hootegem (2000) "How the Japanese got teams", 43-49 in S. Procter \& F. Mueller (Eds.) Teamworking. Houndmills, Basingstoke: Macmillan.

Brodkin, E. (2011) "Policy work: Street-level organizations under new managerialism". Journal of Public Administration Research and Theory 21 (2):253-277. https://doi. org/10.1093/jopart/muq093

Carter, B., A. Danford, D. Howcraft, H. Richardson, A. Smith \& P. Taylor (2011) "Lean and mean in the civil service: The case of processing in HMRC", Public Money \& Management 31 (2):115-122. https://doi.org/10.1080/09540962.2011.5 60708

Clarke, J. (2005) "Performing for the public: Doubt, desire and the evaluation of public services”, 211-232 in P. du Gay (Ed.) The values of bureaucracy. Oxford: Oxford University Press.

Eriksson, E. (2015) Sanktionerat motstand. Brukarinflytande som fenomen och praktik. Lund: Lund University.

Etzioni, A. (1961) A comparative analysis of complex organizations: On power, involvement, and their correlates. New York: Free Press.

Ezzamel, M. \& H. Willmott (1998) "Accounting for teamwork: A critical study of group-based systems of organizational control”, Administrative Science Quarterly 43 (2):358-396. https://doi.org/10.2307/2393856

Finn, R., M. Learmonth \& P. Reedy (2010) "Some unintended effects of teamwork in healthcare”, Social Science \& Medicine 70 (8):1148-1154. https://doi.org/10.1016/j. socscimed.2009.12.025

Fransson, M. \& J. Quist (2018) Fri som en fågel: En studie av återprofessionalisering inom Försäkringskassan. Karlstad: Service Research Center, Karlstad University. 
Försäkringskassan (2016) Verksamhetsplan 2016. Stockholm: Försäkringskassan.

Holmgren Caicedo, M., M. Mårtensson Hansson \& K. Tamm Hallström (2015) När handläggaren blev teammedlem: Om autonomi, lärande och styrning i Försäkringskassan. ISF-rapport 2015:13. Stockholm: Inspektionen för socialförsäkringen.

ISF (2018) Förändrad styrning av och i Försäkringskassan: En analys av hur regeringens mål om ett sjukpenningtal på 9,0 sjukdagar påverkar handläggningen av sjukpenning. ISF-rapport 2018:16. Stockholm: Inspektionen för socialförsäkringen.

Jacobsson, K., Y. Wallinder \& I. Seing (2020) "Street-level bureaucrats under new managerialism: A comparative study of agency cultures and caseworker role identities in two welfare state bureaucracies", Journal of Professions and Organization 7 (3):313-333. https://doi.org/10.1093/jpo/joaa015

Knights, D. \& D. McCabe (2003) "Governing through teamwork: Reconstituting subjectivity in a call centre", Journal of Management Studies 40 (7):1587-1619. https:// doi.org/10.1111/1467-6486.00393

Kunda, G. (2006[1992]). Engineering culture: Control and commitment in a high-tech corporation. Second edition. Philadelphia: Temple University Press.

Lipsky. M. (2010[1980]) Street-level bureaucracy. New York: Russel Sage Foundation. McKinlay, A. \& K. Starkey (1998) "Managing Foucault: Foucault, management and organization theory", 1-13 in A. McKinlay \& K. Starkey (Eds.) Foucault, management and organization theory: From panoptic on to technologies of self. London: Sage. https://doi.org/10.4135/9781446221686.n1

Procter, S. \& F. Mueller (2000) “Teamworking: Strategy, structure, systems and culture", 3-24 in S. Procter \& F. Mueller (Eds.) Teamworking. Houndmills, Basingstoke: Macmillan.

Procter, S. \& G. Currie (2004) “Target-based team working: Groups, work and interdependence in the UK civil service”, Human Relations 57 (12):1547-1572. https:// doi.org/10.1177/0018726704049989

Procter, S. \& Z. Radnor (2014) “Teamworking under Lean in UK public services: Lean teams and team targets in Her Majesty's Revenue \& Customs (HRMC)”, The International Journal of Human Resource Management 25 (21):2978-2995. https:// doi.org/10.1080/09585192.2014.953976

Regeringen (2021) Regleringsbrev för budgetåret 2021 avseende Försäkringskassan. Ändringsbeslut 2021-04-08. Stockholm: Socialdepartementet.

Rutz, S. \& A. de Bont (2020) "Organized discretion”, 279-294 in T. Evans \& P. Hupe (Eds.) Discretion and the quest for controlled freedom. Cham: Palgrave Macmillan. https://doi.org/10.1007/978-3-030-19566-3_18

Saario, S., J.-M. Räsänen \& C. Hall, C (2017) "Negotiating boundaries of professional responsibilities in team meetings", 174-195 in K. Juhila, S. Raitakari \& C. Hall (Eds.) Responsibilization at the margins of welfare services. London: Routledge. https://doi.org/10.4324/9781315681757

Smith, D. (2005) Institutional ethnography. Walnut Creek: AltaMira Press. 


\section{Authors}

Kerstin Jacobsson is professor in sociology at the University of Gothenburg. She conducts research in the field of organization, governance, employment and labor market policy. Other research interests concerns social movements and civil society and sociology of emotions.

Katarina Hollertz is a lecturer in social work at the University of Gothenburg. Her research interests are in the field of social work practice, street level bureaucracies and labor market policies.

\section{Corresponding author}

Kerstin Jacobsson

Department of Sociology and Work Sciences, University of Gothenburg Box 720, 40530 Göteborg, Sweden

kerstin.jacobsson@gu.se 